\title{
Arrhythmogenic Nitro-Oxidative Stress: A Working Hypothesis in Chagas' Heart Disease
}

\author{
Roberto Coury Pedrosa ${ }^{1 *}$, Rozangela Curi Pedrosa ${ }^{2}$ and Danilo Wilhelm Filho ${ }^{3}$ \\ ${ }^{1}$ Department of Cardiology, Federal University of Rio de Janeiro, Brazil \\ ${ }^{2}$ Department of Biochemistry, Federal University of Santa Catarina, Brazil \\ ${ }^{3}$ Department of Ecology and Zoology, Federal University of Santa Catarina, Brazil
}

Submission: June 24, 2019; Published: July 08, 2019

*Corresponding author: Roberto Coury Pedrosa, Department of Cardiology, Clementino Fraga Filho University Hospital/Edson Saad Heart Institute, Federal University of Rio de Janeiro, Brazil

\begin{abstract}
We still need to learn a lot about the effects of redox therapy on complex ventricular arrhythmia in Chagas heart disease (ChHD), caused by the parasite Trypanosoma cruzi. The evidence has pointed toward oxidative stress and the consequent loss of modulation of redox signaling as an important pathogenic factor in ventricular arrhythmias in ChHD. The central purpose of this article will be to promote a better understanding of the arrhythmic influence of the loss of redox signaling-ROS and RNS modulation, focusing on the arrhythmogenic mechanisms of complex ventricular arrhythmias. Still, we will provide the reader a therapeutic rationality in relation to antioxidant and complex ventricular arrhythmias.

Keywords: Chagas heart disease; Trypanosoma cruzi; Oxidative stress; Ventricular arrhythmia; Arrhythmogenic mechanisms

Abbreviations: ChD: Chagas Disease; ChHD: Chagas heart disease; SCA: Sudden Cardiac Arrest; ICD: Implantable Cardioverter Defibrillator; ROS: Reactive Oxygen Species; GCS: Gamma-glutamylcysteine Synthetase; SOD2/ MnSOD: Superoxide dismutase - Mn; iNOS : NO synthase; TNF- $\alpha$ : Tumour Necrosis Factor- $\alpha$; DADs: Delayed After Depolarization; QTc: corrected QT interval; NO: Nitric Oxide; VNS: Vagal Nervous System; OS: Oxidative Stress; nNOS/NOS1: Neuronal Nitric Oxide Synthase; RNS: Reactive Nitrogen Species; SIRT1: NAD-dependent deacetylase sirtuin-1; VCA: Ventricular Cardiac Arrhythmias; TBARS: Thiobarbituric Acid Reactive Substances
\end{abstract}

\section{Introduction}

Chagas' disease (ChD), also known as American trypanosomiasis, is a serious chronically debilitating and often fatal human endemic infectious-parasitic affection caused by Trypanosoma cruzi, transmitted through a hematophagous triatomine vector [1]. It is estimated that up to 5,800,000 people in Latin America endemic countries have chronic ChD causing around 12,500 deaths annually. Hundreds of thousands of infected people has migrated to non-endemic areas, mainly in many parts of Europe and North America, becoming an emerging disease and a worldwide problem [2].

Figure 1 show a diagram of the natural history of Chagas disease. There are 2 phases of the human disease: the acute, which begins about 1 week after the initial infection and is usually asymptomatic; and the chronic, which is subdivided into indeterminate and clinical (cardiac, digestive, or mixed) forms. The clinical presentation in cardiac form is usually mild (80$90 \%$ ) with annual incidence relatively low (1.85\%). The Figure 2 displays a proposed algorithm to guide diagnosis in patients with Chagas heart disease (ChHD).

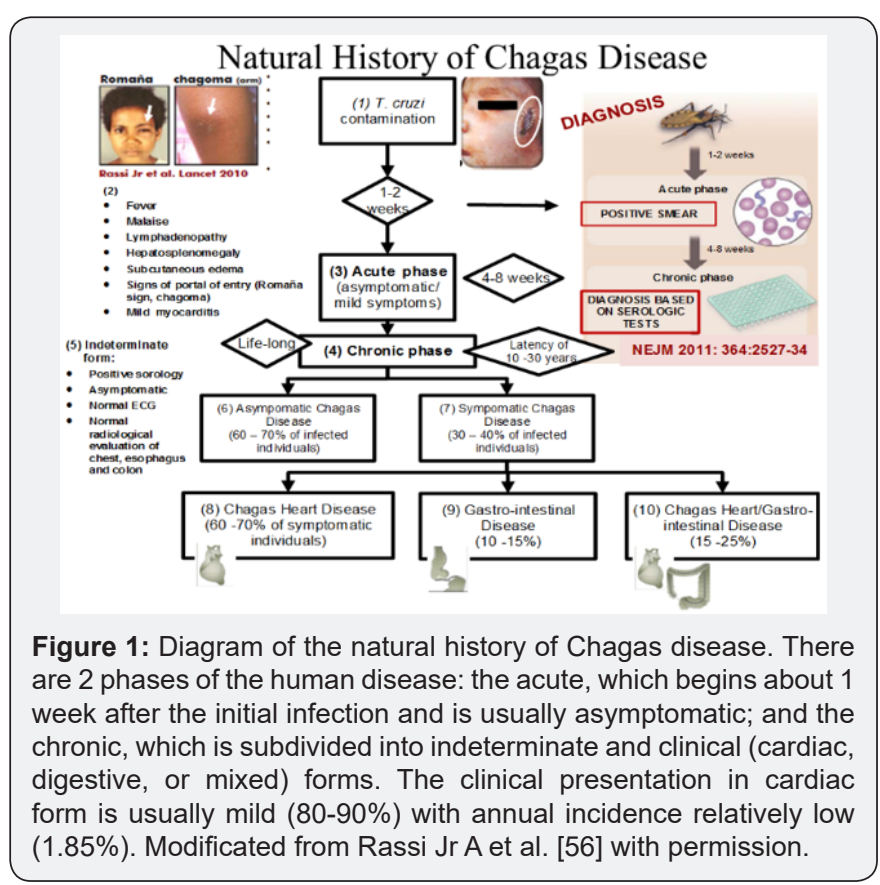




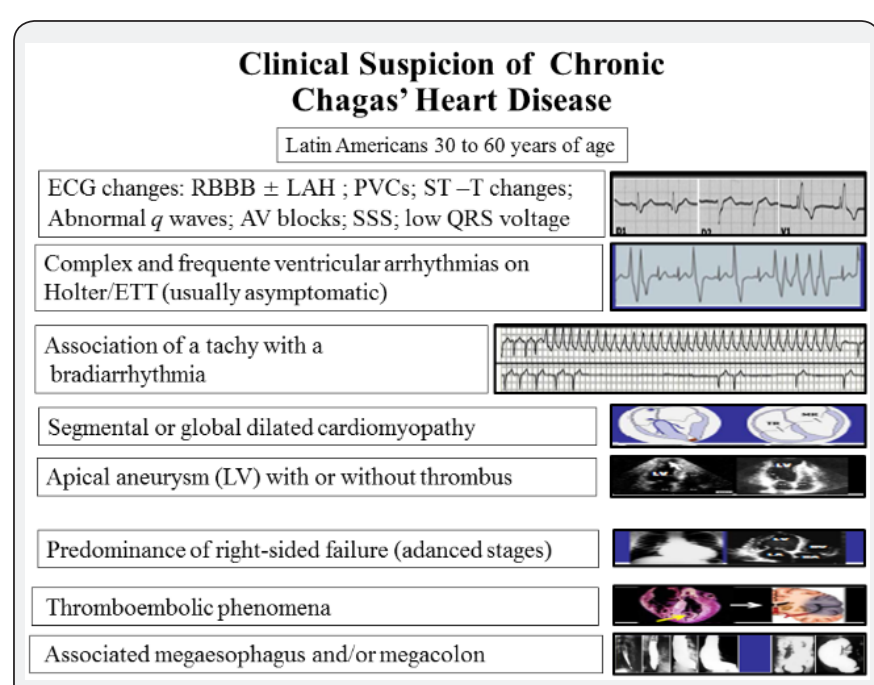

Figure 2: Proposed algorithm to guide diagnosis in patients with Chagas heart disease. People of risk to acquiring Chagas disease (people who lives in rural areas of South America, Central America and Mexico under poor housing conditions that contains infected bugs; who receives a blood transfusion or organ transplant from an infected donor; Children who are born from an infected mother) with ECG showing the 3 most typical alterations: right bundle branch block, left anterior hemiblock and ventricular extra systole. Two-dimensional echocardiogram showing left ventricular apical aneurysm with (arrow) and without thrombus. Modificated from Rassi Jr A et al. [56] with permission.

There is a consensus that for every chagasic patient with evidence of cardiac involvement we should consider the potential risk of death (annual mortality rate of 39/1000 patients) and of annual sudden cardiac arrest (SCA) rate of 24/1000 patients in the cardiac form of the disease) [3-5]. SCA is one of the main ways of death in ChHD and can occur at any stage of the disease [6]. The risk of SCA is related to the presence of ventricular arrhythmias, $10 \%$ are due to a first arrhythmic event in ChHD. At moment, in patients with ChHD, there is no data to support recommendations of implantable cardioverter defibrillator (ICD) for the primary prevention of sudden death and ICD are empirically and commonly used for secondary prevention with significant economic burden [5]. This is due to the fact that the mechanisms underlying these lethal arrhythmias are still poorly understood despite decades of research.

Typically, ChHD is characterized by a persistent chronic active myocarditis as resulted of an amplified immunoinflammatory response among other processes by generation of reactive oxygen species (ROS) in the presence of the parasite or its antigens [713]. It suggests that ChHD is, at least partially, a ROS-dependent pathology (Figure 3). In fact, in the last fifteen years, this concept of loss of redox signaling-ROS modulation has increased $[14,15]$. In addition, the incidence of ventricular arrhythmias, the leading cause of SCA, is associated with progression and extension of inflammatory processes, and, probably is especially related to re-entry pathways generated by resultant patchy fibrosis $[2,6,12,13,16,17]$. So, it is reasonable to speculate that loss of redox signaling-ROS modulation can be regarded as a potential driver of cardiac arrhythmia in ChHD.

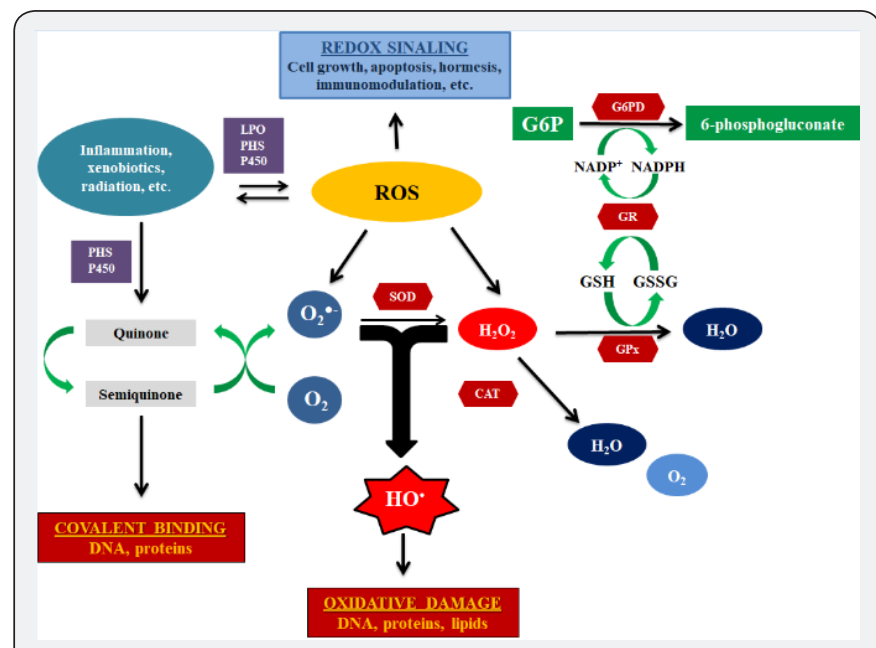

Figure 3: Schematic view of reactive oxygen species production. Diagram showing the inflammatory process leading to oxidative damage through the production of reactive oxygen species.

\section{Pathogenesis of ChHD with special focus on Oxidative} Stress

Mounting evidence have suggested that macrophages, neutrophils and natural killer cells control parasite replication in the early stages of human infection [18-21]. Experimental studies have indicated that Tc-derived molecules engage toll-like receptors to drive activation of macrophages and neutrophils that then produce oxidative burst $[11,22]$. Some studies have demonstrated that oxidative burst is due to mitochondrial oxidative dysfunction due to T. cruzi-induced intracellular $\mathrm{Ca}^{+2}$ flux, required for parasite invasion. The mitochondrial inefficiency in the setting of oxidative phosphorylation continues during the disease chronic phase $[23,24]$ resulting in an inadequate coupling of the respiratory chain with oxidative phosphorylation and an excessive release of electrons to molecular oxygen, leading to an increased mitochondrial ROS production. The role played by ROS-producing macrophages at the chronic stage of infection has been little evaluated and it is still a matter of debate whether indeed oxidative environments provide ideal conditions (e.g., iron availability in macrophages) for T. cruzi growth and whether indeed redox signaling directly to stimulate growth. Garg et al considered the activation of SIRT1 a potential means to restore mitochondrial respiratory chain activity and oxidative phosphorylation capacity as well as to induce mitochondrial biogenesis, processes they found earlier to be impaired in the myocardium of chronically infected rodents [25]. The declines in left-ventricle function and in the expression of Nrf2, HO-1, and gamma-glutamylcysteine synthetase (GCS) were prevented in the hearts of Superoxide dismutase - SOD2 (MnSOD) super expressing transgenic mice [26]. Mice that are deficient for the IFN-y receptor and inducible -NO synthase (iNOS) showed an increased infection risk [27]. Experimental studies in animals infected with Trypanosoma 
cruzi are suggestive that drugs, which attenuate oxidative stress, prevent evolution of cardiac injury [28-30].

Studies in humans have provided indirect evidence for the oxidative function of activated macrophages and neutrophils [12,31-34]. It was recently demonstrated the interlinked effects of inflammatory responses, antioxidant status and oxidant levels in human ChHD [12,26,35]. These interlinked effects were thought to be related to heart function damaged. Thus, protection against ROS has the potential to decrease tissue damage in ChD [36-38]. Since then, several publications have followed this idea [36-40]. Our research group have shown that the progression of cardiac involvement in human ChD [7] might be mediated by ROS, and that the use of antioxidant vitamins $\mathrm{E}$ and $\mathrm{C}$ was effective in attenuating such oxidative insult in the different stages of cardiac involvement of the disease [7-10].

The central purpose of this manuscript will be to promote a better understanding of the arrhythmic influence of the loss of redox signaling-ROS modulation, focusing on the arrhythmogenic mechanisms of complex ventricular arrhythmia. Still, we will provide the reader a therapeutic rationality in relation to antioxidant and complex ventricular arrhythmias

\section{Oxidative stress and ventricular arrhythmias in ChHD}

Studies relating ventricular arrhythmias and ROS in ChHD are scarce, and the current load of knowledge relies largely on studies transposed from other cardiomyopathies.

Information on how alterations of ROS may alter ventricular arrhythmia susceptibility are still to be fully understood. Many of the experimental observations agree with the more limited number of human studies. Mice engineered to over-express tumour necrosis factor- $\alpha$ (TNF- $\alpha$ ) have been commonly used as a model of congestive HF, exhibiting many ion channel conductance abnormalities and increased susceptibility to induced arrhythmias compared to wild-type controls [41]. These are associated with change in the electrical restitution property of the heart and dysregulated intracellular calcium homoeostasis [42]. Accumulation of ROS resultant from loss of modulation of redox signaling very possibly by over boarding inflammation may lead to cardiac $\mathrm{Ca}^{++}$overload, and then induce delayed after depolarization (DADs), which is likely to initiate triggered activity and ventricular arrhythmias. It was reported that complex ventricular arrhythmias may be derived from calcium wave [43] and caused by diastolic calcium leakage [44]. When the calcium wave reaches threshold potential, DADs are induced, leading to ventricular arrhythmia or even SCA. These abnormal findings were corroborated in an experimental mouse model of T. cruzi infection that showed shortens corrected QT interval (QTc) after the intervention of the antioxidant resveratrol [36]. These effects of ROS leading to cardiac $\mathrm{Ca}++$ overload in animal's studies have been consistent in the related literature and point to as the mechanism underlying in the ventricular arrhythmogenesis. Although the full mechanism of action remains to be elucidated, several research groups have explored the possibility that nitric oxide $(\bullet \mathrm{NO})$ is involved in both central and peripheral aspects of vagal control in terms cardiac arrhythmogenesis [45]. In the last years, studies have shown that stimulation of the vagal nervous system (VNS) makes induction of VF more difficult underscoring that VNS has a direct and prominent electrophysiological effect on the ventricular myocardium. It was also showed that this antifibrillatory effect is associated with a change in the electrical restitution property of the heart [45], which is considered a key mechanistic factor in the initiation of ventricular fibrillation [46]. These effects are blocked during nitric oxide synthase (NOS) inhibition, providing indirect evidence that $\bullet \mathrm{NO}$ is involved [47]. A further study showed direct evidence that VNS lead to the release of $\bullet \mathrm{NO}$ in the ventricle via neuronal nitric oxide synthase (nNOS/NOS1) activation [48]. This effect was showed in other related studies $[49,50]$. At the same time, it is known that nNOS is present in many parasympathetic neurones innervating the heart [51] and there is also evidence of a subpopulation of intracardiac nerve fibres that contain solely $\bullet \mathrm{NO}$ coursing towards the ventricle in humans [52]. It has been postulated to cause electrical restitution property disturbances and to ultimately leading to the development of complex ventricular arrhythmias [53,54]. These results indicate a physiological role of these intermediaries in loss of modulation of redox signaling with important impact on ventricular arrhythmogenesis.

In many aspects the ChHD follows a pattern like that described in experimental models of Oxidative stress (OS), via overgeneration of ROS and RNS disturbances in the ventricle. The mechanistic studies identifying i) the mediators produced by cardiomyocytes in response to Trypanosoma cruzi infection, that may trigger the migration of leukocytes and other cells to the heart; ii) the signaling mechanisms regulated by the inflammatory cytokines (e.g. TNF- $\alpha$ and IL-1) that may evoke cell survival/cell growth or cell death responses in chagasic myocardium; and iii) the destructive effects of "oxidative burst" of activated inflammatory cells in ChHD, are discussed elsewhere [35]. Nevertheless, highly complex interactions are far from being completely clarified, mainly regarding the basic mechanisms, thereby creating difficulties in understanding the extensive cardiac damage in chronic chagasic patients. With the increased demonstration of overgeneration of ROS and RNS disturbances in ChHD, the hypothesis that ROS may contribute, at least in part, to ventricular arrhythmogenesis in ChHD has gained plausibility $[35,47,48]$.

Recently, in a study reported by our group, we speculate a possible beneficial effect of the antioxidant supplementation limiting the arrhythmic consequences of chronic inflammatory response, which is so common in ChHD. We showed that the etiological treatment with benznidazole followed by supplementation with the antioxidant vitamins $\mathrm{E}$ and $\mathrm{C}$ decreased episodes of complex ventricular arrhythmias in patients with severe ChHD [55] as showed in Figure 4. Therefore, the antioxidant 
supplementation was above all be capable of restoring the balance of redox signaling [56].

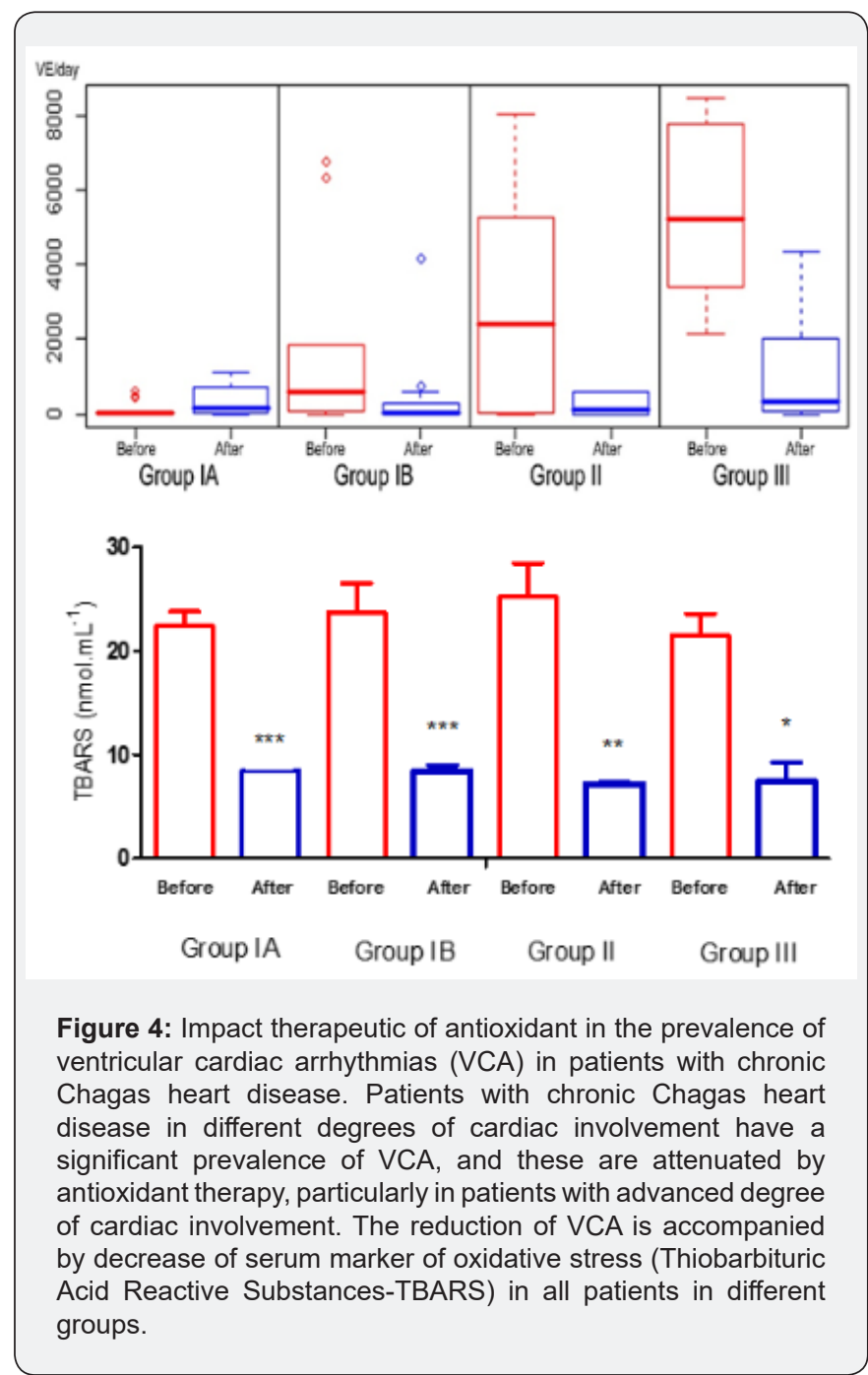

\section{Conclusion}

A relevant and often ignored facet of chronic $\mathrm{ChD}$ is the presence, in all chagasic patients in the cardiac form, of ROS and the consequent loss of modulation of redox signaling. It is reasonable to speculate that ROS can be regarded as a potential driver of cardiac arrhythmia in ChHD. Consequently, to counteract the arrhythmogenic potency of ROS and RNS, strategies that focus on restoration of the balance of redox signaling could be helpful for chagasic patients with complex ventricular arrhythmias, who are refractory to conventional treatments. Not treating a patient with ChHD and complex ventricular arrhythmia is an active and more difficult decision to make than to proceed with the doubt. Nevertheless, a formal proof-of-concept clinical trial is needed to determine if this novel approach is safe and effective in ChHD. Because $\mathrm{ChD}$ is a neglected disease that kills thousands of persons each year, novel and innovative therapies should urgently be tested.

\section{Acknowledgement}

The authors wish to acknowledge the contributions of Valdelucia Maria Alves de Souza Grinevicius for figures. The authors are grateful to the financial support provided by the Brazilian governmental agencies Conselho Nacional de Pesquisa (CNPq). RCP (Proc. 302404/2017-2) are recipients of research grants from CNPq, Brazil.

\section{References}

1. Chagas C (1909) Übereineneue Trypanosomiasis des Menschen. Archiv für Schiffs-und Tropen - Hygiene 8: 5-7.

2. Rassi A Jr, Rassi A, Marcondes de Rezende J (2012) American trypanosomiasis (Chagas disease). Infect Dis Clin North Am 26(2): 275-291.

3. Laranja FS (1953) Clinical aspects of Chagas' disease. Rev Bras Med 10: 482-491.

4. Rassi A, Rezende JM, Luquetti AO (2010) Clinical phases and forms of Chagas disease. In: American trypanosomiasis (Chagas disease). One hundred years of research, Telleria J, Tibayrenc M (eds). Burlington: New York, USA, pp. 709-741.

5. Nunes MCP, Beaton A, Acquatella H, Bern C, Bolger AF, et al. (2018) Chagas Cardiomyopathy: An Update of Current Clinical Knowledge and Management A: Scientific Statement From the American Heart Association. Circulation 138(12): e169-e209.

6. Rassi AJr, Rassi SG, Rassi A (2001) Sudden death in Chagas' disease. Arq Bras Cardiol 76(1): 75-96.

7. de Oliveira TB, Pedrosa RC, Filho DW (2007) Oxidative stress in chronic cardiopathy associated with Chagas' disease. Int J Cardiol 116(3): 357363.

8. Maçao LB, Wilhelm Filho D, Pedrosa RC, Pereira A, Backes P, et al. (2007) Antioxidant therapy attenuates oxidative stress in chronic cardiopathy associated with Chagas' disease. Inter J Cardiol 123(1): 43-49.

9. Ribeiro CM, Budni P, Pedrosa RC, Farias MS, Parisotto EB, et al. (2010) Antioxidant therapy attenuates oxidative insult caused by benzonidazole in chronic Chagas' heart disease. Int J Cardiology 145(1): 27-33.

10. Budni P, Pedrosa RC, Garlet TR, Dalmarco EM, Dalmarco JB, et al (2012) Carvedilol attenuates oxidative stress in chronic Chagasic cardiomyopathy. Arq Bras Cardiol 98(3): 218-224.

11. Cardoni RL, Antunez MI, Morales C, Nantes IR, et al. (1997) Release of reactive oxygen species by phagocytic cells in response to live parasites in mice infected with Trypanosoma cruzi. Am J Trop Med Hyg 56(3): 329-334.

12. Machado FS, Dutra WO, Esper L, Gollob KJ, Teixeira MM, et al. (2012) Current understanding of immunity to Trypanosoma cruzi infection and pathogenesis of Chagas disease. Semin Immunopathol 34(6): 753770 .

13. Paiva CN, Medei E, Bozza MT (2018) ROS and Trypanosoma cruzi: Fuel to infection, poison to the heart. PLoS Pathog 14(4): e1006928.

14. Fernandes DC, Bonatto D, Laurindo FRM (2010) The evolving concept of oxidative stress. In: Oxidative stress in clinical practice: Cardiovascular Diseases, Sauer H, Shah A, Laurindo FR (eds.). Springer: New York, pp. 1-41.

15. Ristow M, Zarse K, Oberbach A, Klöting N, Birringer M, et al. (2009) Antioxidants prevent health-promoting effects of physical exercise in humans. Proc Natl Acad Sci U S A 106(21): 8665-8670. 
16. Marin-Neto JA, Rassi A, Maciel BC (2010) Chagas heart disease. In Evidence-based cardiology, S. Yusuf S, Cairns JA, Camm AJ, Fallen EL, Gersh BJ (eds). BMJ Books: London, UK pp. 823-841.

17. Tanowitz HB, Wen JJ, Machado FS (2016) Trypanosoma cruzi and Chagas disease: innate immunity, ROS, and cardiovascular system. In: Vascular Responses to Pathogens, Gavins NE, Stokes KY, Waltham MA (Eds). Academic Press: London, UK, pp. 183-193.

18. Diez RA, Estevez ME, Sen L, Barousse AP, Laplumme H (1985) Defective intracellular lysis in macrophages from chronic chagasic patients. Ann Trop Med Parasitol 79(3): 339-340.

19. Arnholdt AC, Piuvezam MR, Russo DM, Lima AP, Pedrosa RC, et al. (1993) Analysis and partial epitope mapping of human T cell responses to Trypanosoma cruzi cysteinyl proteinase J Immunol 151(6): 31713179.

20. Pedrosa RC, Saad EA, Scharfstein J, Lima AM (1996) The proliferative response of $\mathrm{T}$ cells against cruzipain in chronic chagasic cardiopathy. Rev Soc Bras Med Trop 29(4): 331-339.

21. Vitelli-Avelar DM, Sathler-Avelar R, Dias JC, Pascoal VP, TeixeiraCarvalho A, et al. (2005) Chagasic patients with indeterminate clinical form of the disease have high frequencies of circulating CD3+CD162CD56+ natural killer T cells and CD4+CD25 high regulatory T lymphocytes. Scand J Immunol 62(3): 297-308.

22. Melo RC, Fabrino DL, D’Avila H, Teixeira HC, Ferreira AP (2003) Production of hydrogen peroxide by peripheral blood monocytes and specific macrophages during experimental infection with Trypanosoma cruzi in vivo. Cell Biol Int 27(10): 853-861.

23. Ba X, Gupta S, Davidson M, Garg NJ (2010) Trypanosoma cruzi induces ROS-PARP-1-RelA pathway for up regulation of cytokine expression in cardiomyocytes. J Biol Chem 285(15): 11596-11606.

24. Dhiman M, Garg NJ (2011) NADPH oxidase inhibition ameliorates Trypanosoma cruzi-induced myocarditis during Chagas disease. J Pathol 225(4): 583-596.

25. Wan X, Wen JJ, Koo SJ, Liang LY, Garg NJ (2016) SIRT1-PGC1alphaNFkappaB Pathway of Oxidative and Inflammatory Stress during Trypanosoma cruzi Infection: Benefits of SIRT1-Targeted Therapy in Improving Heart Function in Chagas Disease. PLoS Pathog 12(10): e1005954.

26. Wen JJ, Porter C, Garg NJ (2017) Inhibition of NFE2L2-Antioxidant Response Element Pathway by Mitochondrial Reactive Oxygen Species Contributes to Development of Cardiomyopathy and Left Ventricular Dysfunction in Chagas Disease. Antioxid Redox Signal 27(9): 550-566.

27. Hölscher C, Köhler G, Müller U, Mossmann H, Schaub GA, et al. (1998) Defective nitric oxide effector functions lead to extreme susceptibility of Trypanosoma cruzi-infected mice deficient in gamma interferon receptor or inducible nitric oxide synthase. Infect Immun 66(3): 12081215.

28. Wen JJ, Garg NJ (2008) Mitochondrial generation of reactive oxygen species is enhanced at the $\mathrm{Q}(\mathrm{o})$ site of the complex III in the myocardium of Trypanosoma cruzi-infected mice: beneficial effects of an antioxidant. J Bioenerg Biomembr 40(6): 587-598.

29. Wen JJ, Gupta S, Guan Z, Dhiman M, Condon D, et al. (2010) Phenyl$\alpha$-tert-butylnitrone and Benzonidazole Treatment Controlled the Mitochondrial Oxidative Stress and Evolution of Cardiomyopathy in Chronic Chagasic Rats. J Am College Cardiol 55(22): 2499-2508.

30. Gupta S, Smith C, Auclair S, Delgadillo Ade J, Garg NJ (2015) Therapeutic Efficacy of a Subunit Vaccine in Controlling Chronic Trypanosoma cruzi Infection and Chagas Disease Is Enhanced by Glutathione Peroxidase Over-Expression. PLoS One 10: e0130562.
31. Wen JJ, Yachelini PC, Sembaj A, Manzur RE, Garg NJ (2006) Increased oxidative stress is correlated with mitochondrial dysfunction in chagasic patients. Free Rad Biol Med 41(2): 270-276.

32. Muniz-Junqueira MI, Mota LM, Aires RB, Junqueira Júnior LF (2004) Differing phagocytic function of monocytes and neutrophils in Chagas' cardiopathy according to the presence or absence of congestive heart failure. Rev Soc Bras Med Trop 37(6): 447-453.

33. Sathler-Avelar R, Vitelli-Avelar DM, Teixeira-Carvalho A, Martins-Filho OA (2009) Innate immunity and regulatory T-cells in human Chagas disease: what must be understood?. Mem Inst Oswaldo Cruz 104 Suppl 1: 246-251.

34. Wan X, Gupta S, Zago MP, Davidson MM, Dousset P, et al. (2012) Defects of mtDNA replication impaired the mitochondrial biogenesis during Trypanosoma cruzi infection in human cardiomyocytes and chagasic patients: The role of Nrf1/2 and antioxidant response. J Am Heart Assoc 1(6): e003855.

35. Dhiman M, Coronado YA, Vallejo CK, Petersen JR, Ejilemele A, et al. (2013) Innate Immune Responses and Antioxidant/Oxidant Imbalance Are Major Determinants of Human Chagas Disease. PLoS Negl Trop Dis $7(8)$ : e2364.

36. Vilar-Pereira G, Carneiro VC, Mata-Santos H, Vicentino AR, Ramos IP, et al. (2016) Resveratrol Reverses Functional Chagas Heart Disease in Mice. PLoS Pathog 12(10): e1005947.

37. Guedes PM, Oliveira FS, Gutierrez FR, da Silva GK, Rodrigues GJ, et al. (2010) Nitric oxide donor trans- [RuCNO] as a possible therapeutic approach for Chagas' disease. Br J Pharmacol 160(2): 270-282.

38. Sesti-Costa R, Carneiro ZA, Silva MC, Santos M, Silva GK, et al. (2014) Ruthenium complex with benznidazole and nitric oxide as a new candidate for the treatment of Chagas disease. PLoS Negl Trop Dis 8(10): e3207.

39. Nagajyothi F, Zhao D, Weiss LM, Tanowitz HB (2012) Curcumin treatment provides protection against Trypanosoma cruzi infection. Parasitol Res 110(6): 2491-2499.

40. Jelicks LA, de Souza AP, Araujo-Jorge TC, Tanowitz HB (2011) Would selenium supplementation aid in therapy for Chagas disease? Trends Parasitol 27(3): 102-105.

41. Petkova-Kirova PS, Gursoy E, Mehdi H, McTiernan CF, London B, et al. (2012) Electrical remodeling of cardiac myocytes from mice with heart failure due to the overexpression of tumor necrosis factor-alpha. Am J Physiol Heart Circ Physiol 290(5): H2098-H2107.

42. London B, Baker LC, Lee JS, Shusterman V, Choi BR, et al. (2003) Calcium dependent arrhythmias in transgenic mice with heart failure. Am J Physiol Heart Circ 284(2): H431-H441.

43. Blayney LM, Lai FA (2009) Ryanodine receptor-mediated arrhythmias and sudden cardiac death. Pharmacol Ther 123(2): 151-177.

44. Duan DD (2010) A leakage leads to failure: roles of sarcoplasmic reticulum $\mathrm{Ca} 2+$ leak via RyR2 in heart failure progression. Hypertension 55(4): 849-851.

45. Ng GA, Brack KE, Patel VH, Coote JH (2007) Autonomic modulation of electrical restitution alternans and ventricular fibrillation initiation in the isolated heart. Cardiovasc Res 73(4): 750-760.

46. Weiss JN, Chen PS, Qu Z, Karagueuzian HS, Lin SF, et al. (2002) Electrical restitution and cardiac fibrillation. J Cardiovasc Electrophysiol 13(3): 292-295.

47. Brack KE, Patel VH, Coote JH, Ng GA (2007) Nitric oxide mediate the vagal protective effect on ventricular fibrillation via effects on action potential duration in the isolated rabbit heart. J Physiol 583(Pt 2): 695704. 
48. Brack KE, Patel VH, Mantravadi R, Coote JH, Ng GA (2009) Direct evidence of nitric oxide release from neuronal nitric oxide synthase activation in the left ventricle as a result of cervical vagus nerve stimulation J Physiol 587(Pt 12): 3045-3054.

49. Kumar K (2000) Percutaneous nitroglycerin administration into the intact pericardial space suppresses ischemia-induced ventricular arrhythmias in closed-chest pigs. PACE-Pacing Clin Electrophysiol 23: 730-31.

50. Ng GA, Mistry A, Li X, Schlindwein FS, Nicolson WB, et al. (2018) LifeMap: towards the development of a new technology in sudden cardiac death risk stratification for clinical use. Europace 20(F12) 162-170.

51. Singh S, Gray T, Wurster RD (2009) Nitric oxide and carbon monoxide synthesizing enzymes and soluble guanylyl cyclase within neurons of adult human cardiac ganglia. Auton Neurosci 145(1-2): 93-98.
52. Hoover DB, Isaacs ER, Jaques F, Hoard JL, Pagé P, et al. (2009) Localization of multiple neurotransmitters in surgically derived specimens of human atrial ganglia. Neuroscience164(3): 1170-1179.

53. Ng GA (2016) Neuro-cardiac interaction in malignant ventricular arrhythmia and sudden cardiac death. Auton Neurosci 199: 66-79.

54. Ng GA (2014) Vagal modulation of cardiac ventricular arrhythmia. Exp Physiol 99(2): 295-299.

55. Barbosa JL, Thiers CA, de Bragança Pereira B, do Nascimento EM, Ribeiro Frazon CM, et al. (2016) Impact of the Use of Benznidazole Followed by Antioxidant Supplementation in the Prevalence of Ventricular Arrhythmias in Patients with Chronic Chagas Disease: Pilot Study. Am J Ther 23(6): e1474-e1483.

56. Rassi Jr A (2014) Chagas Heart Disease: A New Challenge for the Cardiologist Outside Latin America. Conference paper, World Congress of Cardiology Scientific sessions. Melbourne, Australia, pp. 4-7.

Your next submission with Juniper Publishers
will reach you the below assets
- Quality Editorial service
- Swift Peer Review
- Reprints availability
- E-prints Service
- Manuscript Podcast for convenient understanding
- Global attainment for your research
- Manuscript accessibility in different formats
( Pdf, E-pub, Full Text, Audio)
- Unceasing customer service
Track the below URL for one-step submission
https://juniperpublishers.com/online-submission.php

